\title{
Effect of rubella vaccination programme in schools on rubella immunity in a general practice population
}

\author{
DAVID GILMORE, ERNEST T ROBINSON, W HARPER GILMOUR, GEORGE E D URQUHART
}

\begin{abstract}
Between November 1979 and January 1980 all patients aged 13-21 years who attended a general practice in Glasgow were tested for their immunity against rubella (single radial haemolysis test). All of the women in the sample should have been vaccinated at 13 as part of the rubella vaccination programme, which began in Glasgow in 1971. The programme excludes boys.

Of the 77 female and 64 male patients studied, nine $(11.7 \%)$ and $10(15.6 \%)$, respectively, were susceptible to the infection. For only 34 women was evidence of vaccination documented in the practice records, and three of those either had failed to seroconvert or had antibody below detectable values. Overall there was no significant difference between the proportion of men and women who were susceptible to the disease.

The rubella vaccination programme had clearly failed to reduce the number of susceptible women in this practice. Hence the immune state of all girls should be checked at about 15 years of age, so that as many as possible may be rendered immune before they leave school.
\end{abstract}

\section{Introduction}

Programmes of immunisation against rubella are designed to prevent the consequences of infection at a particular point in a woman's life-during early pregnancy. Thus while immunity in, say, over $80 \%$ of the population may be acceptable for some conditions, success with rubella depends on achieving, in women, immune rates close to $100 \%$ in advance of the childbearing years. In contrast with, say, the United States, British policy is directed only at girls and at achieving individual immunity through vaccination. Hence general practitioners are anxious to ensure that all young women on their lists are immune to rubella before their first pregnancy. The general practitioner, however, cannot identify from his records those who have had natural infection from those who have not, those who were vaccinated from those who were not, and those who were vaccinated and failed to seroconvert. At present, therefore, he identifies the immune state of all pregnant women attending his antenatal clinic and vaccinates those who are seronegative in the early postpartum period. But he must also investigate and counsel those women who might have rubella or be in contact with rubella infection in early pregnancy.

In Glasgow a rubella immunisation programme began in March 1971, when all 13-year-old girls were offered vaccination. The names of those vaccinated are notified to the appropriate

Woodside Health Centre, Glasgow G20 7LR

DAVID GILMORE, MB, trainee general practitioner (currently registrar, Obstetric Division, Stobhill Hospital, Glasgow G12 3UW) ERNEST T ROBINSON, FRCGP, general practitioner

University Department of Statistics, Glasgow G12 $8 Q Q$ W HARPER GILMOUR, MSC, FIS, statistician

Regional Virus Laboratory, Ruchill Hospital, Glasgow G20 9NB GEORGE E D URQUHÁRT, MB, FRCPATH, consultant virologist general practitioner. The proportion of girls vaccinated varied little during $1975-8$, the overall proportion being $86.6 \%$ (table I). Cendevax was used until 1977 and Almevax, said to give more lasting immunity, used thereafter. From 1977 the policy was to offer vaccination to all girls in their first year at secondary school.

TABLE I-Rubella vaccination rates in Glasgow schools during 1975-8

\begin{tabular}{lccccc}
\hline & 1975 & 1976 & 1977 & 1978 & Total \\
\hline No due & 7473 & 9902 & 9021 & 7764 & 34160 \\
No $(\%)$ vaccinated & $6560(87 \cdot 8)$ & $8460(85 \cdot 4)$ & $7884(87 \cdot 4)$ & $6686(86 \cdot 1)$ & $29590(86 \cdot 6)$
\end{tabular}

We report the effect of the rubella immunisation programme on the immune state of a sample of women in our practice using a similar male sample as control.

\section{Population and method}

Our practice in Woodside Health Centre serves an urban population with serious social deprivation; most of our patients are in social classes IV and V. In 1979 the rubella immunisation rate for girls in our health district was $82 \% .^{1}$ Between November 1979 and January 1980 all male and female patients who consulted their doctor for reasons other than problems related to rubella infection and who were born between March 1958 and March 1966 were asked to give a sample of blood for estimation of rubella immune state. The women in the sample should have been offered rubella vaccination at 13 years of age. We searched our records for evidence of vaccination in the women. Haemagglutination inhibition and single radial haemolysis estimations were conducted at the Regional Virus Laboratory, Glasgow. At present it is generally accepted that persons with haemagglutination inhibition titres of $1 / 8$ or less or single radial haemolysis of less than $7 \mathrm{~mm}$ (less than $15 \mathrm{IU} / \mathrm{ml}$ ), or both, may be regarded as susceptible to rubella infection. Single radial haemolysis is the more reliable test for screening. When the test was first introduced in Glasgow in 1979 a $5 \mathrm{~mm}$ zone was equivalent to $15 \mathrm{IU}$ of antibody. In 1980 this was altered for technical reasons to give a zone of $7 \mathrm{~mm}$ with the $15 \mathrm{IU}$ control.

\section{Results}

The sample consisted of 141 persons, 77 female and 64 male. Their mean age was 17.8 years (table II). Nine $(11.7 \%$ ) of the women

TABLE II-Age, sex, and immune state of sample

\begin{tabular}{|c|c|c|c|c|c|}
\hline \multirow{2}{*}{ Vaccine } & \multirow{2}{*}{$\begin{array}{c}\text { Age } \\
\text { (years) }\end{array}$} & \multicolumn{2}{|c|}{ Male patients } & \multicolumn{2}{|c|}{ Female patients } \\
\hline & & Total & $\underset{\text { susceptible }}{\text { No }}$ & Total & $\begin{array}{c}\text { No } \\
\text { susceptible }\end{array}$ \\
\hline $\begin{array}{c}\text { Almevax } \\
\text { \#, } \\
\text { Cendevax } \\
\text { ”, } \\
\text { \# } \\
\text { \# }\end{array}$ & $\begin{array}{l}13 \\
14 \\
15 \\
16 \\
17 \\
18 \\
19 \\
20 \\
21 \\
22\end{array}$ & $\begin{array}{r}3 \\
8 \\
5 \\
8 \\
5 \\
4 \\
4 \\
10 \\
8 \\
6 \\
7 \\
\end{array}$ & $\begin{array}{l}1 \\
1 \\
0 \\
1 \\
0 \\
2 \\
1 \\
1 \\
2 \\
1\end{array}$ & $\begin{array}{r}3 \\
5 \\
4 \\
9 \\
14 \\
9 \\
15 \\
7 \\
9 \\
2 \\
\end{array}$ & $\begin{array}{l}0 \\
0 \\
0 \\
0 \\
4 \\
0 \\
2 \\
0 \\
2 \\
1 \\
\end{array}$ \\
\hline Total & & 64 & 10 & 77 & 9 \\
\hline
\end{tabular}


and $10(15.6 \%)$ of the men were susceptible. There was no difference in median age between susceptible male and female patients (MannWhitney test). All nine susceptible women were in the age groups offered vaccination with Cendevax (table II). Figures 1 and 2 show proportionally the results of the haemagglutination inhibition and single haemolysis tests. By haemagglutination inhibition 13 women $(16.9 \%)$ and 10 men $(15.6 \%)$ were susceptible. By single radial haemolysis nine women $(11.7 \%)$ and 10 men $(15.6 \%)$ were susceptible. Evidence of vaccination was found in the records of 34 of the women; three $(8.8 \%)$ of them were susceptible by haemagglutination inhibition and by single radial haemolysis. Figures 1 and 2 show proportionally the amounts of circulating antibody in the 34 women.

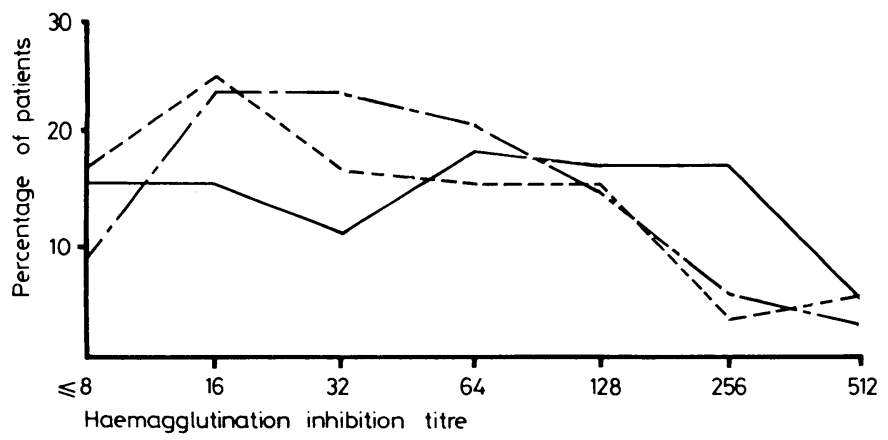

FIG 1-Proportions of male ( - ), female (-- - ), and vaccinated female $(---)$ patients with haemagglutination inhibition titres of $1 / 8$ or less to $1 / 512$.

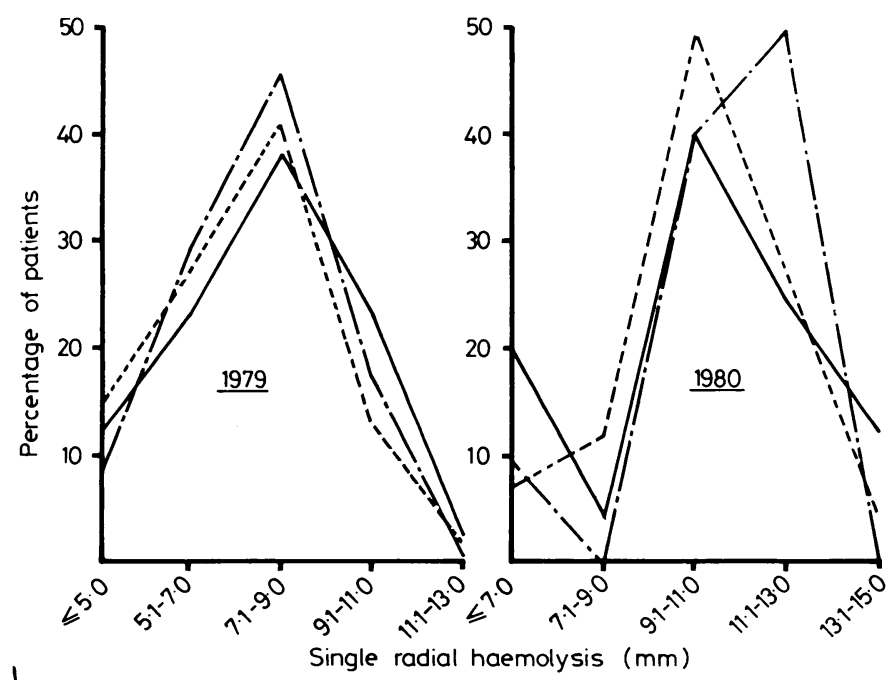

FIG 2-Proportions of male (-), female (-- - ), and vaccinated female $(---)$ patients with single radial haemolysis zones of $5 \mathrm{~mm}$ or less to $13 \mathrm{~mm}$ in 1979 and $7 \mathrm{~mm}$ or less to $15 \mathrm{~mm}$ in 1980. (Size of zone equivalent to $15 \mathrm{IU}$ antibody recalibrated in 1980 from $5 \mathrm{~mm}$ to $7 \mathrm{~mm}$.)

\section{Discussion}

Our results show that the rubella immunisation programme in schools has not significantly reduced the number of susceptible women in our practice. Ten $(15.6 \%)$ of the male sample were susceptible compared with nine $(11 \cdot 7 \%)$ of the female sample. If the samples are regarded as random samples from populations in relevant age groups, the $95 \%$ confidence interval for the true difference in the proportions of susceptible men and women was $3.9 \pm 11.4 \%$. This difference is not statistically significant. Possibly the 1978-9 rubella epidemic affected more male than female patients. ${ }^{2}$ The difference in immune antibody state between men and women measured by haemagglutination inhibition and single radial haemolysis was not significant when compared by the Mann-Whitney test. Within the sample four of the women were immune by single radial haemolysis and susceptible by haemagglutination inhibition. This difference may be accounted for by the fact that the inhibition test cannot differentiate between low level antibody and non-specific inhibitor, whereas the radial haemolysis test is not affected by non-specific inhibition. Although there was no significant difference in the proportion of male and female patients susceptible to rubella, whether determined by each test alone or in combination, the number of women who could be regarded as susceptible varied from nine when determined by both tests to 13 by haemagglutination inhibition alone.

Surprisingly few women recall having rubella vaccination at school, and a history of clinical rubella is unreliable. In only 34 women who should have been vaccinated did we find evidence of vaccination in the records. This was partly due to the high mobility of our population but also to the difficulty of reliable communication of written evidence of vaccination to the record envelope. A further problem may be the effectiveness of the vaccines employed or the method of use by the School Health Service, though our finding that the women for whom records were available had adequate immunity in general suggests that this aspect of the programme was satisfactory. Three out of 34 vaccinated women failed to seroconvert or had antibody that had fallen to undetectable values by both the haemagglutination inhibition and single radial haemolysis tests, creating a problem for the physician caring for the individual woman.

The combined requirements for a programme directed at preventing the sequelae of congenital rubella infection are those of ensuring that all women reaching childbearing age are immune and that the immune state of the individual woman should be available to those responsible for her antenatal care. We conclude that these requirements are not being satisfied, so that it becomes necessary to consider alternative strategies. One alternative would be to assess routinely the immune state of all schoolgirls at, say, 15 years of age; this would also allow maximum opportunity for acquired natural immunity. After this assessment, those who were seronegative could be vaccinated and their immune state rechecked. Defaulters could be followed up more vigorously, since they would be known to be at definite risk. Checking the immune state of the girls who were vaccinated would permit vaccines to be monitored and ensure that the immune state of girls was known at the time of leaving school.

Tables III and IV show the present strategy compared with that proposed above. At present the School Health Service

TABLE III-Estimate of costs for 100 women

\begin{tabular}{|c|c|}
\hline Existing policy & Proposed policy \\
\hline \multicolumn{2}{|c|}{ At school } \\
\hline $\begin{array}{l}85 \text { vaccine doses } \\
\text { Cost of giving } 85 \text { injections }\end{array}$ & $\begin{array}{l}100 \text { serotests } \\
\text { Cost of } 100 \text { venepunctures } \\
30 \text { vaccine doses (assume } 70 \% \text { immune) } \\
\text { Cost of } 30 \text { injections } \\
30 \text { check serotests } \\
\text { Cost of } 30 \text { venepunctures }\end{array}$ \\
\hline \multicolumn{2}{|c|}{ At antenatal clinic } \\
\hline $\begin{array}{l}100 \text { serotests } \\
100 \text { venepunctures } \\
15 \text { vaccine doses (assume } 85 \% \text { immune) } \\
\text { Cost of } 15 \text { injections } \\
15 \text { recheck serotests } \\
\text { Cost of } 15 \text { venepunctures }\end{array}$ & Assume all costs occur at school \\
\hline
\end{tabular}

TABLE IV-Comparison of costs

\begin{tabular}{|c|c|c|c|c|}
\hline & \multicolumn{2}{|c|}{ Existing policy } & \multicolumn{2}{|c|}{ Proposed policy } \\
\hline & No & Cost $(£)$ & No & Cost $(£)$ \\
\hline $\begin{array}{l}\text { Cost } / 100 \text { women: } \\
\text { Vaccine doses }(£ 1.56 / \text { dose }) \\
\text { Serotests }(£ 0 \cdot 50 / \text { test }) \\
\text { Venepuncture/injections }\end{array}$ & $\begin{array}{l}100 \\
115 \\
215\end{array}$ & $\begin{array}{r}156 \cdot 00 \\
57 \cdot 50\end{array}$ & $\begin{array}{r}30 \\
130 \\
160 \\
\end{array}$ & $\begin{array}{l}46.80 \\
65.00\end{array}$ \\
\hline Total & & 213.50 & & $111 \cdot 80$ \\
\hline Cost for 8500 Glasgow schoolgirls & & $18147 \cdot 50$ & & $9508 \cdot 10$ \\
\hline
\end{tabular}


participates only in giving, say, 85 vaccine doses for every 100 girls offered vaccination, with a major part of the checking of immune state delayed to the stage of the antenatal clinic. The comparison does not include the repetition of tests which may occur between general practitioners and hospitals. In our proposed strategy activities of the antenatal clinic would be transferred to the school, which would increase the cost of the School Health Service but greatly reduce the cost in the antenatal sector. These cost savings would be substantial. Table IV compares the cost of the present system (which for vaccine and serotests we estimate as $£ 213.50$ per 100 women) with that of our proposed strategy, which takes advantage of the benefit of natural immunity. The cost per 100 women by this approach is about $£ 112$ for the serotests and vaccine, a saving of some $48 \%$. The annual saving in a city such as Glasgow with a need to vaccinate 8500 girls a year would be about $£ 9000$.

Similar arrangements apply to the need for blood grouping, which may even be repeated for the same person in each pregnancy. Blood taken for estimating rubella immunity could also be used to determine blood group, and there are clear benefits from women having an early knowledge of both blood group and rubella immunity. An extension of our proposal w might be to provide a card for all schoolgirls on which to record their blood group, immune state, immunisation, and other relevant information. Probably such a card would be preserved and the information available later to those responsible for their care with a consequent improvement in patient care at no additional cost.

We acknowledge the help given by Drs L W J Ross and A E Burton. We thank Professor J H Barber and Dr F A Boddy, University of Glasgow, for advice in the preparation of this paper.

\section{References}

1 Greater Glasgow Health Board Information Services Unit. Maternity and child health statistics 1974-1979. Glasgow: Greater Glasgow Health Board, 1980.

2 Communicable Diseases Scotland. Annual summary of viral chlamydial, $\vec{\circ}$ rickettsial, and mycoplasmal diseases. Glasgow: Communicable Diseases Unit, 1978.

(Accepted 14 September 1981)

\section{SHORT REPORTS}

\section{Methadone produces prolonged postoperative analgesia}

Recent reports have suggested that postoperative analgesia is often inadequate. ${ }^{1}$ Repeated intramuscular injections of narcotics with a high clearance and a short half life-for example, pethidine, morphine - produce rapidly fluctuating blood concentrations. The consequence of such changes is a clinical response ranging from ineffective analgesia, through analgesia, to unwanted and toxic effects. Adequate control of postoperative pain may be obtained with a blood pethidine concentration of between 400 and $700 \mu \mathrm{g} / 1 .^{1}$ One technique to overcome the fluctuating blood concentrations would be to administer the narcotic by intravenous infusion, either by "demand" or at a continuous rate. ${ }^{2}$ Both infusion methods, however, require fairly expensive infusion pumps. An alternative method of providing continuous analgesia without the problems associated with infusion techniques might be to give, infrequently, a narcotic with a long half life, and low clearance - for example, methadone. We report that methadone produces prolonged postoperative analgesia after a single intravenous dose.

\section{Patients, methods, and results}

Methadone was administered as a $20 \mathrm{mg}$ intravenous bolus (over one minute) when cardiovascular stability returned after induction of anaesthesia in 19 healthy adult patients undergoing elective surgery (anterior spinal fusion 10, cholecystectomy four, other abdominal surgery five). Blood was collected at appropriate time intervals for determination of methadone concentration and hence pharmacokinetics in the postoperative period. No narcotic was used for premedication, and methadone was the only narcotic used during the intraoperative period. A volatile anaesthetic agent (enflurane) was added if the depth of anaesthesia associated with the methadone, nitrous oxide, and relaxant was considered to be inadequate.

Supplementary analgesia in the postoperative period was given at the request of the patients, who had been informed preoperatively that they had the choice of intramuscular (narcotic) or oral (non-narcotic) analgesia when they thought it necessary. Blood was collected immediately before any postoperative analgesic medication was given to calculate the minimum effective analgesic blood methadone concentration and the duration of analgesia. The blood methadone concentration was measured by gas chromatography based on a previous method. ${ }^{3}$ Standard curves were reproducible and passed through the origin, and the limit of sensitivity of the assay was $5 \mu \mathrm{g} / \mathrm{l}$.

Five of the 19 patients $(26 \%)$ did not require any postoperative analgesia. Six patients $(32 \%)$ received non-narcotic analgesics; the median duration of analgesia was 26 hours (range $22-35$ hours) and the median minimum effective blood concentration of methadone $30 \mu \mathrm{g} / 1(18-54 \mu \mathrm{g} / 1)$. Eight patients $(42 \%)$ received an additional narcotic, which was either morphine or pethidine; the median duration of analgesia was 20 hours (nine to 25 hours) and the median minimum effective blood concentration $30 \mu \mathrm{g} / \mathrm{l} N$ $(19-46 \mu \mathrm{g} / 1)$ (table).

No significant respiratory depression (below 10 breaths/minute) was noted. Nausea occurred in nine patients but responded to one or two injections of prochlorperazine. Pharmacokinetic studies indicated that the mean distribution half life of the $20 \mathrm{mg}$ intravenous bolus of methadone was eight minutes while the terminal half life was $35 \cdot 1 \pm \mathrm{SD} 20 \cdot 3$ hours and the clearance $172 \pm 88 \mathrm{ml} / \mathrm{min}$. The mean volume of distribution at steady state was $416 \pm 151$ litres.

Minimum effective analgesic concentration and potency values for narcotic agonists

\begin{tabular}{lccc}
\hline \multirow{2}{*}{ Narcotic } & \multicolumn{2}{c}{$\begin{array}{c}\text { Minimum effective } \\
\text { analgesic concentration } \\
(\mu \mathrm{g} / \mathrm{l})\end{array}$} & Potency* \\
\cline { 2 - 3 } & Blood & Plasma & \\
\hline $\begin{array}{l}\text { Methadone† } \\
\text { Pethidine }\end{array}$ & 35 & $48 \|$ & 1 \\
Morphine§ & 460 & $600 \|$ & $0 \cdot 10-0 \cdot 13$ \\
\hline
\end{tabular}
Blood :plasma ratios calculated from studies performed in this
department indicate values (mean $\pm \mathrm{SD}$ ) of $0 \cdot 77 \pm 0 \cdot 11$ for department indicate values (mean $\pm S D$ )
pethidine and $0.73+0.05$ for methadone.

*From Houde.

+Present study.

$\ddagger$ From reference 1 .

From Dahlstrom et al. ${ }^{4}$ This figure was obtained for pain during operation (in children 7-15 years old), which would be expected to be higher than that necessary to control postoperative pain.

Calculated from blood:plasma ratio $(\lambda)$-that is, plasma concentration $=$ blood concentration $/ \lambda$.

\section{Comment}

The prolonged postoperative analgesia (median value 25 hours) obtained after a single intravenous dose of methadone is similar to the $\widetilde{O}$ terminal half life (mean 35 hours). Furthermore, there appears to be a minimum effective analgesic concentration of methadone (median value $35 \mu \mathrm{g} / \mathrm{l})$. Previous studies ${ }^{1}$ have shown a similar relation for pethidine in the treatment of postoperative pain (mean value $460 \mu \mathrm{g} / \mathrm{l}$ ). Our results suggest that there may be a direct relation between minimum analgesic blood concentration and potency for the narcotic agonists studied (see table).

Pharmacokinetic studies have shown that clearance of methadone is about one-fifth of that of either morphine or pethidine $(0 \cdot 6-0.8$ $1 / \mathrm{min}) .^{2}$ The mean distribution half life was only eight minutes, indicating that the blood methadone concentration falls rapidly after bolus intravenous administration. The distribution phase should therefore be complete 45-60 minutes after administration. The

然

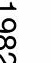

